\begin{tabular}{c} 
journal homepage: http://ijiemjournal. uns.ac.rs/ \\
International Journal of Industrial \\
Engineering and Management \\
Volume $12 /$ No $4 /$ December $2021 / 286-298$ \\
\hline
\end{tabular}

Original research article

\title{
Selecting the best tools and framework to evaluate equipment malfunctions and improve the OEE in the cork industry
}

\author{
P. Marinho ${ }^{a}$, D. Pimentel ${ }^{a}$, R. Casais ${ }^{a}$, F. J. G. Silva ${ }^{a, b, *}$, J. C. Sáa,b, L. P. Ferreira ${ }^{a, b}$ \\ a ISEP - School of Engineering, Polytechnic of Porto, Rua Dr. António Bernardino de Almeida, 431, 4200-072 Porto, Portugal \\ b INEGI - Instituto de Ciência e Inovação em Engenharia Mecânica e Engenharia Industrial, Rua Dr. Roberto Frias, 400, $4200-465$ \\ Porto, Portugal
}

\section{ABSTRACT}

Total Productive Maintenance (TPM) has gain increasing relevance into the companies, which can help in increasing the productivity due to less equipment stoppages. The unavailability of the equipment directly affects the company's performance, which can be measured through the OEE. However, the organization of SMEs is not always properly organized, to have a concrete sense of the losses that can accumulate due to equipment unavailability. This work aimed to develop a framework capable of responding effectively in the beginning of the implementation process of a TPM system. A novel sequence of application of tools was created, both linked to lean and quality, which, when applied in the correct sequence, allow solving some persistent problems in a few steps, resulting in significant gains for companies. The model was applied to a company in the cork industry, and it was possible to verify its effectiveness.

\section{ARTICLE INFO}

Article history:

Received May 21, 2021

Revised November 2, 2021

Accepted November 4, 2021

Published online November 16, 2021

Keywords:

Maintenance,

TPM,

TPM pillars,

Pareto's chart,

Ishikawa,

Five Whys,

Cork industry,

SME.

${ }^{*}$ Corresponding author:

F. J. G. Silva

fgs@isep.ipp.pt

\section{Introduction}

In view of the high competitiveness of the markets, industries need to show constant improvements and changes, whether in terms of their production systems or in terms of their equipment, thus seeking to keep their levels of competitiveness. To keep this competitiveness, companies must adopt continuous improvement measures to tackle all sources of waste in the production processes, and in the rest of the organization, with the objective of increasing profitability [1,2]. As such, the introduction of the Total Productive Maintenance (TPM) methodology allows organizations to make the most of their resources in an effective way, by eliminating losses, reducing breakdowns and, consequently, reducing costs. This methodology addresses well-defined concepts of maintenance, where it is essential to ensure that its application is started by top managers and ends on the operators [3]. 
The TPM was developed through the combination of American preventive maintenance and Japanese concepts of total quality management, implying total employee involvement. This was developed by Seiichi Nakajima [4], in Japan, to support lean production systems that focus on reducing losses. According to McKone [5], the TPM is a program that deals with the maintenance of equipment, through a comprehensive system of productive maintenance, monitoring the useful life of the equipment and involving all production and maintenance employees along with top management. In addition, the TPM is also a methodology and a philosophy of strategic equipment management, focused on the creation of quality products, through the maximization of equipment [6]. The objectives of the TPM must consider the objectives of the organization, that is, an alignment of these must be made with the global vision of the company. The fundamental goals of any TPM program are based on improving productivity and quality, as well as increasing employee morale and satisfaction in the workplace [7]. Thus, the key objectives of the TPM can be defined as [8,9]: maximizing the effectiveness of the equipment by optimizing the availability, performance, efficiency and product quality, establishing a preventive maintenance strategy for the entire life cycle of the equipment, the involvement of all departments of the organization, the involvement of all employees, from senior management to operators, promoting training actions for operators and maintenance technicians to improve and refine their knowledge and reduce waste.

This work aimed to develop a framework capable of responding effectively in the beginning of the implementation process of a TPM system, to tackle the main problems related to breakdowns and persistent production failures. It is intended to create a novel sequence of application of tools, linking Lean and Quality, which, when applied in the correct sequence, allows solving some persistent problems in a few steps, resulting in significant gains for companies.

\section{Background and Methodology}

Due to market globalization, competitiveness has been increasing, which encourages companies to find solutions that aim for cost reduction. Therefore, and with the increasingly high demands from customers regarding quality, there is a need to avoid interruptions. One of these solutions is the use of maintenance as a tool that allows not only to increase the availability of equipment but also to reduce waste, thus resulting in increased productivity [10]. According to Deac et al. [11] and Ferreira et al. [12], maintenance represents a set of measures and actions that guarantee the prevention, preservation, and restoration of equipment to a previous state or to be able to ensure the realization of a particular service, together with minimizing the maintenance costs. For Robertson [13], maintenance objectives are described as the following: (a) Guarantee safety; (b) Maintain quality; (c) Improve availability to increase productivity; (d) Reduce costs.

Maintenance actions are generally classified into two types: Preventive Maintenance (PM) and Corrective Maintenance (CM). For Erkoyuncu [14], PM is the process in which inspections, tests, measurements, adjustments, or replacements of components are carried out, specifically designed to avoid failures. These preventive actions are carried out at predetermined intervals. On the other hand, CM follows the principle of "run to failure", where the action will consist of replacing a defective system, subsystem, or component to guarantee a complete and flawless restoration of the operational condition.

In today's highly dynamic and rapidly changing environment, global competition between organizations has led to higher standards from companies. Consequently, there is a demand for performance improvements, focusing on cutting costs and increasing productivity and quality levels to satisfy customers. All of this has given impetus to leading organizations around the world to adopt effective and efficient maintenance strategies, such as the TPM, over the traditional approaches of "firefighting" reactive maintenance [15]. The TPM can be defined as an improvement program that establishes a comprehensive productive maintenance system, throughout the life of the equipment, covering all fields related to the equipment. This tool depends on the participation of all employees, to promote maintenance through motivation or voluntary team activities [4]. Briefly, the goals of any TPM program are based on improving productivity and quality (zero defects, zero losses and zero waste), as well as increasing employee morale and job satisfaction $[9,16]$. According to Pinto et al. [3], the partial implementation of the TPM methodology, i.e., the use of only a few pillars, can provide very positive results.

For the implementation of the TPM, it was necessary to establish guiding conceptual elements, which were defined as pillars, to guide the development of this tool [17]. The definition of the pillars is varied and personalized according to the requirements of the company. The TPM model initially proposed by 
Nakajima [4] had only five pillars. Later, the JIPM -Japan Institute of Plant Maintenance presented a model with eight pillars, which are as depicted in Table 1.

Although the eight pillars described above constitute the support, the TPM starts with the $5 \mathrm{~S}$ methodology, which is considered as the foundation or base of the TPM [6]. The $5 \mathrm{~S}$ methodology is one of the best tools to generate a change in the attitude of workers and serves as a way of involving improvement activities in the workplace. The name $5 \mathrm{~S}$ corresponds to the first letter of five Japanese words - Seiri (Sort), Seiton (Set in order), Seiso (Shine), Seiketsu (Standardize), Shitsuke (Sustain). This methodology, developed in Japan, introduces good habits related to the organization and cleanliness of the company, with the application of $5 \mathrm{~S}$ to be considered as a prerequisite for the implementation of other improvement actions and as a basic step to eliminate waste [18,22]. According to Ribeiro et al. [23], the use of 5S tools, supported by TPM, was very important to find the root cause of the existing high number of failures in one line's equipment.

This work has a greater impact on the pillars of autonomous maintenance and preventive maintenance. As previously mentioned, autonomous maintenance is one of the pillars of the TPM, following an approach where the responsibility for the maintenance of the equipment is divided between operators and technicians in the maintenance department [24]. The objective is to eliminate all the time losses associated with breakdowns and micro-stops in the production system due to machine failures, which inevitably have a direct impact on the performance of the process [25]. In their daily work with the equipment, operators acquire experience and knowledge related to the handling and diagnosis of the equipment. Therefore, machine operators are the first line of defence against unplanned downtime for production equipment [24]. Also, according to Wudhikarn [24], Overall Equipment Efficiency (OEE) was introduced by Nakajima as an analysis tool to assess the improvement achieved through the development initiatives carried out for the implementation of TPM. OEE is the main metric for measuring the success of TPM implementation programs [26]. This indicator highlights an organization's real "hidden capacity", measuring efficiency (doing things right) and effectiveness (doing what is right). The OEE incorporates three basic indicators of equipment performance and reliability, which are availability (stop losses), performance (speed losses) and quality (default losses), each focusing on different types of losses [25,27]. Therefore, the calculation of the OEE and each of its components is described in Table 2. According to Patel [25], to obtain levels considered world class, the OEE must reach a minimum percentage value of $85 \%$, with a minimum availability of $90 \%$, a minimum performance of $95 \%$ and a minimum quality of $99 \%$.

Table 1. Main pillars of TPM

\begin{tabular}{|c|c|}
\hline Pillar & Description \\
\hline $\begin{array}{l}\text { Autonomous } \\
\text { maintenance }\end{array}$ & $\begin{array}{l}\text { Focuses on the development of operators so that they can perform small } \\
\text { maintenance tasks [18]. }\end{array}$ \\
\hline Focused improvement & $\begin{array}{l}\text { Fundamentally, it aims at the identification and elimination of all losses and, } \\
\text { consequently, to increase the efficiency of equipment, systems and production } \\
\text { processes [19]. }\end{array}$ \\
\hline Planned maintenance & $\begin{array}{l}\text { Defines an optimal level of equipment performance through the implementation of } \\
\text { activities designed to recover the ideal state of the device and maintain that state } \\
\text { through preventive and predictive maintenance activities [17]. }\end{array}$ \\
\hline Maintenance of quality & The focus is on systematically eliminating non-conformities [20]. \\
\hline Education and training & $\begin{array}{l}\text { This is where the initial understanding of the importance of the TPM philosophy is } \\
\text { obtained, through training to enhance skills related to maintaining and improving } \\
\text { the productivity levels of the workplace [17]. }\end{array}$ \\
\hline $\begin{array}{l}\text { Safety, health and } \\
\text { environment }\end{array}$ & $\begin{array}{l}\text { It seeks to guarantee zero accidents, zero occupational diseases and zero } \\
\text { environmental accidents in the workplace [17]. }\end{array}$ \\
\hline Office TPM & $\begin{array}{l}\text { The objectives are to achieve zero functional loss, create highly efficient offices } \\
\text { and provide effective services and support to other departments. Administrative } \\
\text { departments have as main tasks to gather, process and spread information [21]. }\end{array}$ \\
\hline Initial management & $\begin{array}{l}\text { The objectives are to minimize the problems and the execution time in new } \\
\text { equipment, use the learning of existing systems for the application in new systems } \\
\text { and carry out maintenance improvement initiatives [11]. }\end{array}$ \\
\hline
\end{tabular}


Table 2. OEE calculation [25]

\begin{tabular}{ll}
\hline \multicolumn{1}{c}{ Parameter } & \multicolumn{1}{c}{ Calculation } \\
\hline Availability & $=($ Planned Production Time - Downtime Loss $) /$ Planned Production Time \\
Performance & $=($ Ideal Cycle Time $\times$ Total Count $) /$ Run Time \\
Quality & $=($ Total Parts Produced - Total Scrap $) /$ Total count \\
OEE & $=$ Availability $\times$ Performance $\times$ Quality \\
\hline
\end{tabular}

This study was carried out using action research methodology, to develop a model that allows to solve different problems in the production and maintenance departments in a cork company. According to Martins [28], this methodology allows to combine theoretical knowledge with company knowledge, to achieve improvements in the production process (loss reduction). This approach consists of five steps (Figure 1): Diagnosis; Action planning; Implementation; Evaluation; Monitoring.

Following the previous cycle, Table 3 presents an overview of the action research cycle for this work, summarizing the work performed at each step.

\subsection{Diagnosis}

To better understand the impact that each sector has on the time lost in corrective maintenance, a data survey was carried out, to analyse the downtime due to breakdowns in the different sectors. These data correspond to the period between 1 January to 13 November 2019. The workstation that presents the most time lost due to occurrences is the DSL, which has spent 365.48 hours on maintenance, corresponding to $60.71 \%$ of the breakdowns for the period under analysis. This analysis is represented in the chart of Figure 2.

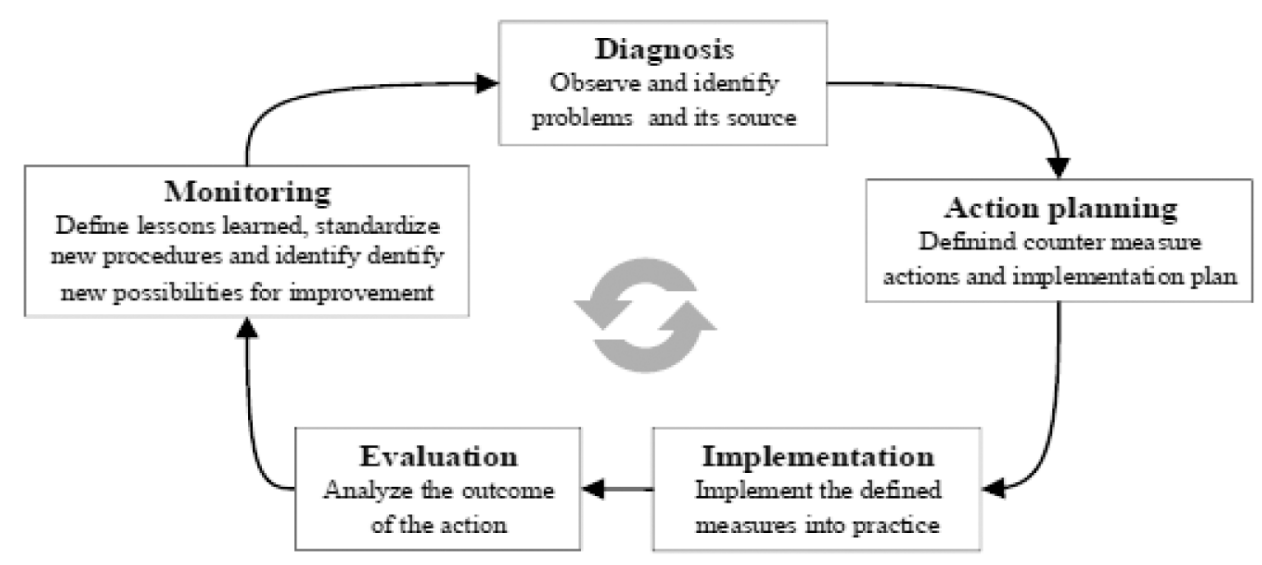

Figure 1. Action research cycle [28]

Table 3. Resume of the action research cycle for this work

\begin{tabular}{ll}
\multicolumn{1}{c}{ Step } & \multicolumn{1}{c}{ Content } \\
\hline Diagnosis & $\begin{array}{l}\text { A brief examination of the various workstations has been performed, to } \\
\text { to carry out an analysis of the causes of these malfunctions, the equipment to be } \\
\text { intervened was identified considering the malfunction history. }\end{array}$ \\
Action planning & $\begin{array}{l}\text { The solutions obtained through the analysis carried out in the Diagnosis phase are } \\
\text { presented and action are defined and planned. }\end{array}$ \\
Implementation & A summary of all the implemented improvement actions is presented. \\
Evaluation & Establishing key performance indicators to analyse the performance. \\
Monitoring & Establishing indicators to control and support future improvements.
\end{tabular}




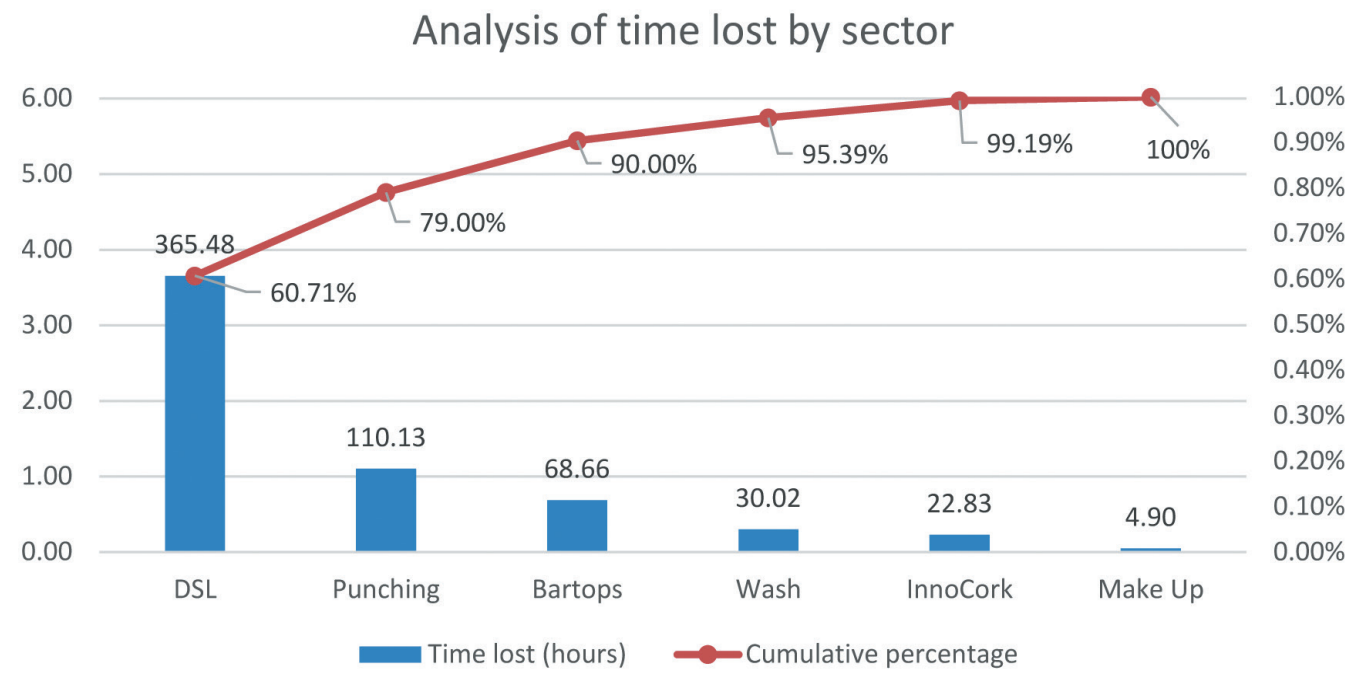

Figure 2. Time lost with malfunctions

In addition to the quantitative analysis, other factors that complemented the choice of this sector were also considered. One of them was the fact that there is equipment in this sector common to other sectors, i.e., some of the improvements carried out in this sector can induce a positive effect in other sectors, eliminating wasted time. This allows for a greater scope and impact of the actions to be implemented. Another factor is the often request from the production department to analyse some recurring problems with the equipment, because successive breakdowns hinder the production rate, affecting the availability and the performance of the department and can cause unexpected delays in delivering the products to the market.

Consequently, it was carried out the gathering, compilation and analysis of data regarding the failures for the electronic sort equipment (ES) for the period from 1 January to 13 November 2019. These data refer to the time needed to repair the failures and not to the equipment downtime during those failures because this is the most reliable data possible to gather, regarding the information collected in the workstations. This happens because many companies do not have automatic report of the time the breakdown starts in reliable terms [3,29,30]. This is a common problem in the shopfloor of SMEs, mainly when there are not sensors, there are no Smart Manufacturing systems implemented, and the education regarding the usual work procedures is not totally respected. This seriously interfere with the data collected, upsurging many doubts about the reliability of the data collected. To perform a serious work, a very close monitoring is needed, as well as a sensitization of the people involved. Moreover, these lacks of reliability also hiddens the possibility of statistically process the data. Therefore, Figure 3 chart contains in-

\section{Pareto's chart - Analysis of malfunctions in DSL (80\%)}

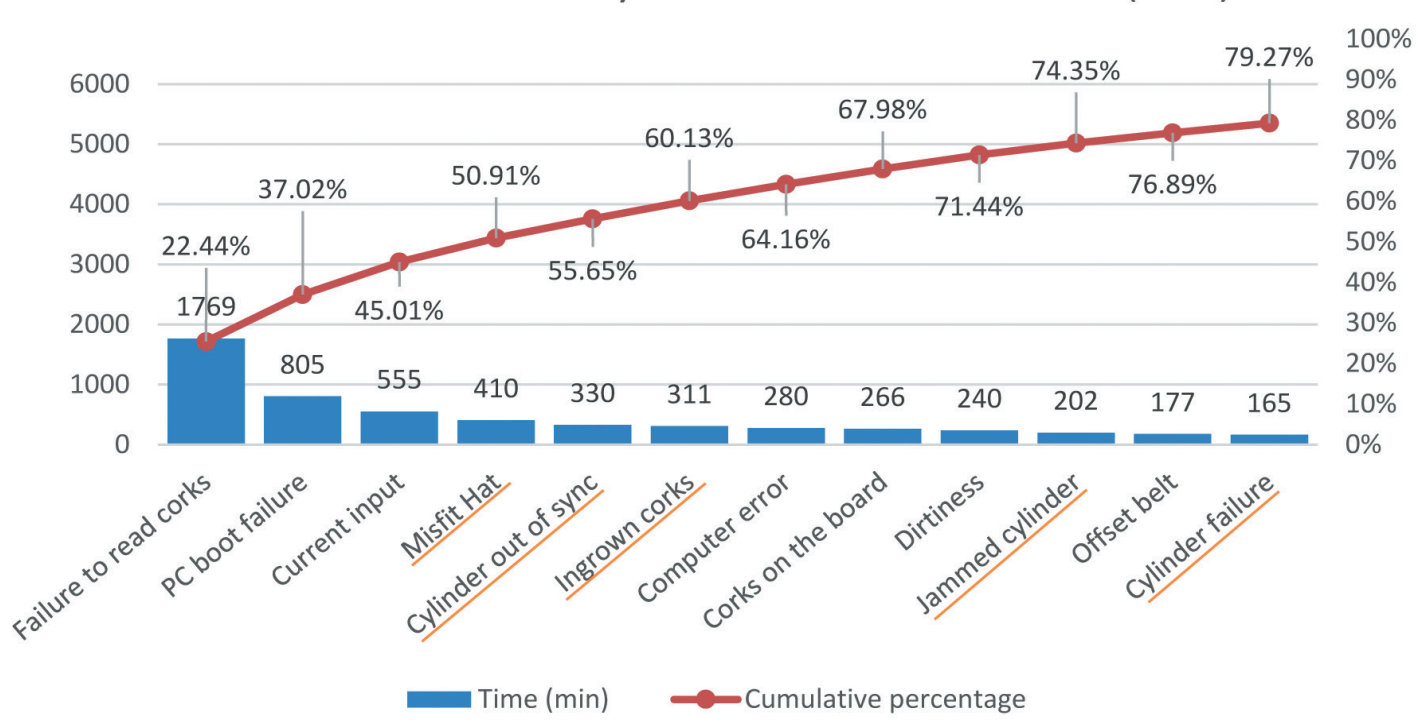

Figure 3. Pareto's chart for DSL malfunctions 
formation regarding the interventions recorded and considered as valid in the period under study and which consume $80 \%$ of the total maintenance time.

In the first phase of this analysis, a verification of all the malfunctions that could have common causes or interactions was made, such as the occurrence "failure to read corks", which could be caused by the "computer error". The exclusive analysis of these data was not enough to understand the failures in their entirety, so the experience of the maintenance technicians and the equipment operators was crucial to this process. Thus, it became clear that most occurrences (marked in green on the Figure 3 chart) originated a failure referred to as "cylinder jam". This occurs when the pneumatic cylinder (Figure 4) cannot function, causing the accumulation of corks inside the ES equipment. This situation leads to the machines stopping, with possible damage to the corks and the equipment. According to the production management software MGPRO, the production department assessed that, for the period from 1 January to 13 November 2019, 296.3 hours of work were lost due to this malfunction in the DSL sector. Consequently, it was decided to address this malfunction, as it is the one that causes the most disturbance.

In the second phase, it was carried out a study of cause-effect relationships for the different malfunctions, to seek out a resolution beyond corrective maintenance interventions. To this end, the experience of the maintenance technicians and the five whys analysis tool were crucial to achieve the desired knowledge. At this stage, it was clear that the most intrinsic knowledge of the ES equipment lies in the maintenance technicians and not in the operators, mainly because the equipment is highly automated, and the operators are not skilled enough to intervene in some systems and devices of the equipment.

To facilitate and structure this analysis, the equipment was divided into two mechanisms, which are the "input" of corks and the "feeding" devices that put the pieces of corks in position to be photographed/digitalized. This information is summarized in the Table 4 with the help of Figure 5 and Figure 6.

Therefore, deep analyses were performed for all components mentioned in Table 2. However, due to the extension of these analyses, it was decided to present only one example in this paper. The component chosen for this purpose was the "Tub (or vibrating

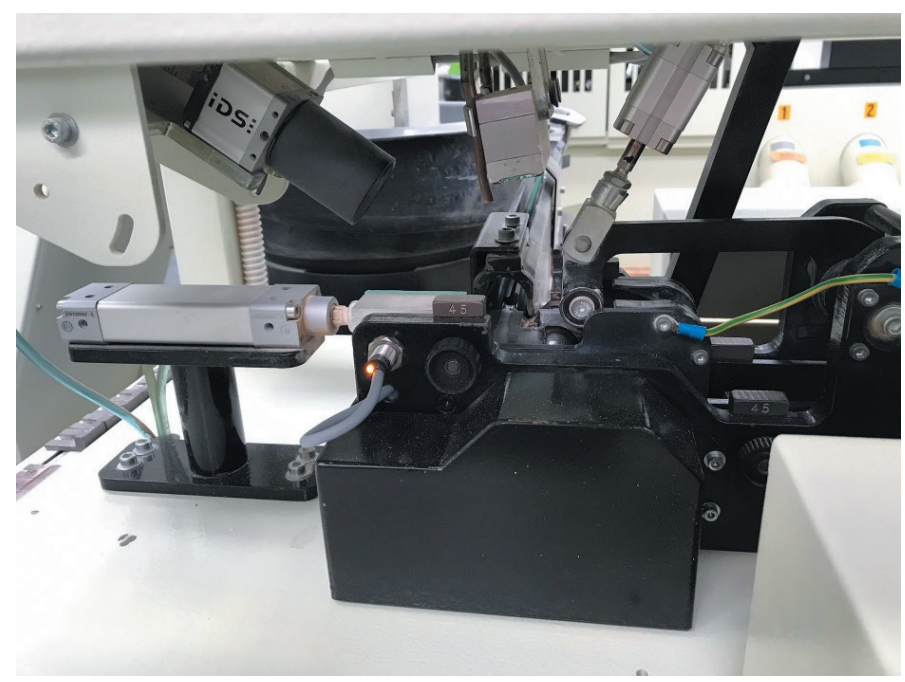

Figure 4. Interior of the electronic sorting (ES) equipment

Table 4. Information regarding the analysis of the structure

\begin{tabular}{lcl}
\hline Mechanism & Components & Figure \\
\hline \multirow{2}{*}{ Input } & Gauge hat & Figure 6.a \\
& Green cords & Figure 5.a \\
& Tub (or vibrating tank) & Figure 5.b \\
Feeding & Feed cylinder & Figure 6.b \\
& Pressure cylinder & Figure 6.c \\
& Knees guides & Figure 6.d \\
\hline
\end{tabular}




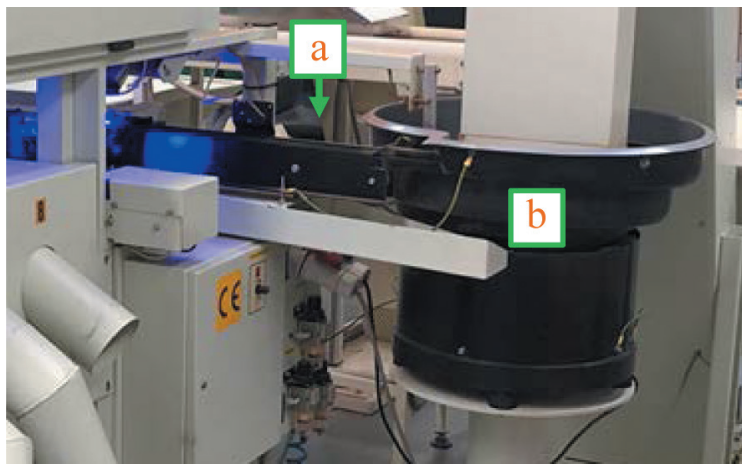

Figure 5. Input mechanism

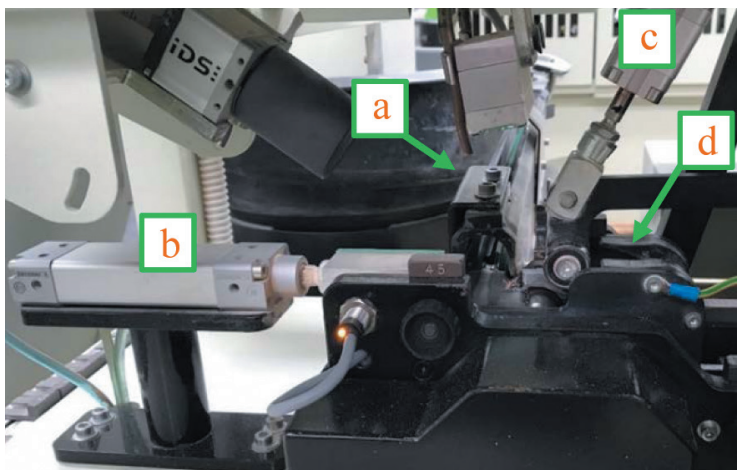

Figure 6. Feeding mechanism

tank)" beacause it is the element subjected to higher levels of mechanical stress, among the different parts studied. This is related to the fact that this component uses vibration to correctly shape the direction of the corks and move them in the right direction.

Regarding the tub, it was necessary to better understand its functioning to understand the possible causes behind its malfunctions or breakdowns. The elements that make up the tub are the inductor (Figure 7.a), which produces vibration, the blades (Figure 7.b), which transfer the vibration to the tub container, the distance between bars of the inductor and the tub container (Figure 7.c), which is responsible for the intensity of the vibration, and the coating of the tub (Figure 8) which facilitates the movement of the corks by reducing friction.

After the application of the Five Whys approach ("Why is the Tub failing?"), four causes were found for the malfunctions of this device, by interviewing the maintenance technicians and the equipment operators, as shown in Figure 9. The first is related to the fracture of the blades (Figure 7.b), wich headed to the first question "Why did the blades break?". The cause for this incident is the wear of the constant vibrating motion to which this component is subjected. Therefore, by extending the usage of the component beyond its theoretical service life, the risk of a possible malfunction that needs corrective intervention is increased. This translates into the need to inter- rupt the production process to restore the normal operation of the equipment and, as a result, the loss of availability. Consequently, this led to the second question, wich is "Why were the blades used beyond their theoretical service life?". The answer lies in the fact that there is little study/knowledge about the service life of the blades. The second cause is related to the inductor fatigue (Figure 7.a). When asking the first question, "Why did the electric transformer wears so much?", it was clear that this problem, like the previous one, is related to the use of the component beyond its theoretical service life. Thus, by asking "Why did the electric transformer was used beyond its theoretical service life?", it was clear that this situation is caused by the lack of maintenance when it comes to checking the condition of this component. The third cause is the distance between bars (Figure 7.c). By asking "Why did the distance between bars was incorrect?", it was clear that this is dependent on the installation of the inductor. Therefore, when installing the inductor, it must be ensured that the distance from the bars is as intended. If this parameter is not correct, the tub will not have the performance required for feeding corks into the equipment. Finally, the fourth cause is related to the coating of the tub (Figure 8). When asking "Why did the tank coating

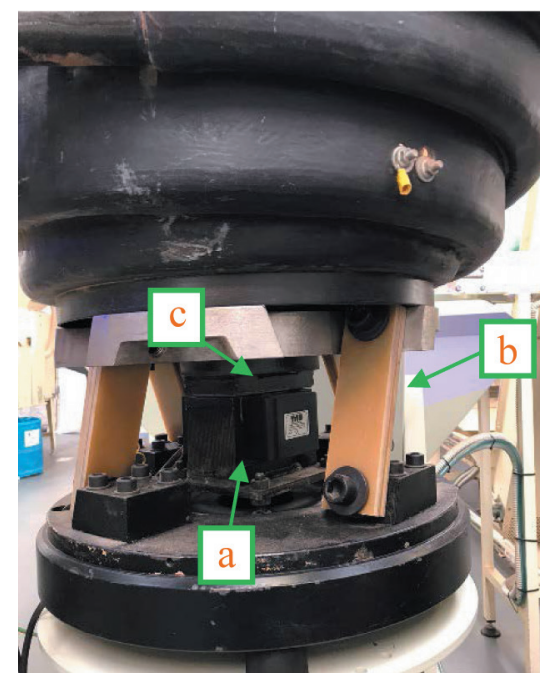

Figure 7. Tub vibration elements

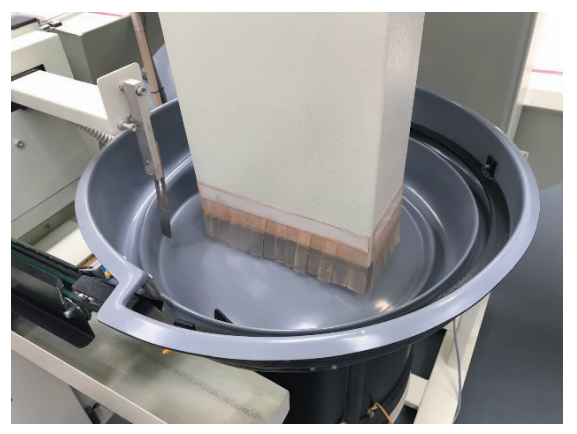

Figure 8. Tub container 


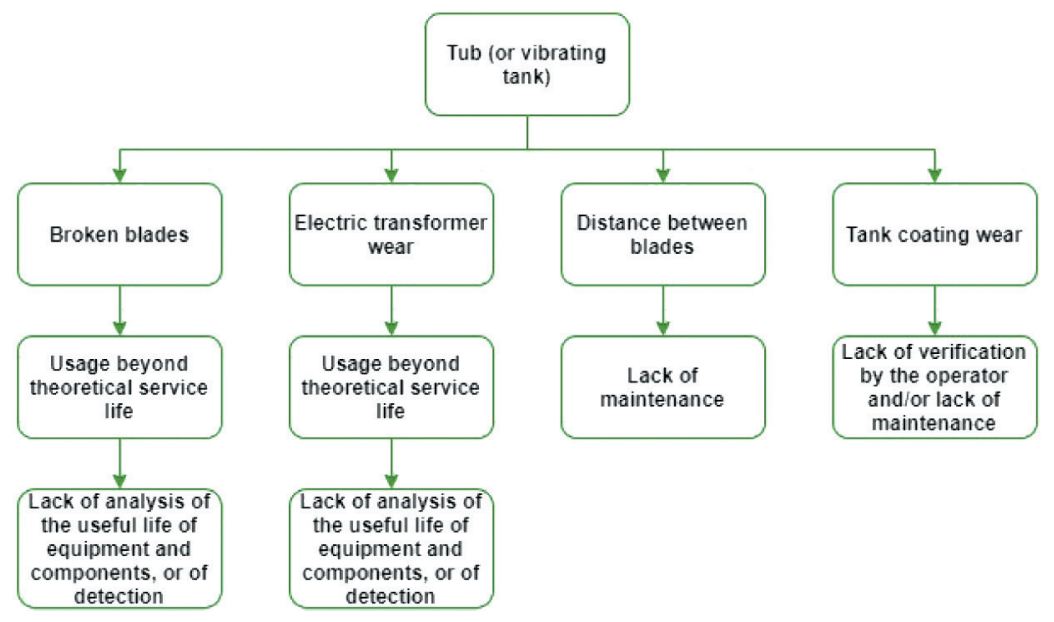

Figure 9. Analysis of the five whys for the tub (Indutor)

wears so much?", it was evident that the wear and tear caused by the repetitive passage of the corks leads to deterioration of the coating, which leads to increased friction and, consequently, a decrease in the speed of supplying corks to the equipment.

\subsection{Action planning}

To prevent the problems described in the previous paragraphs, preventive actions were established for the different elements that make up the tub. To reduce the number of broken blades, it was suggested to measure the vibration of the tub, so that it could be adjusted to the ideal value. This would allow to extend the service life of the component. However, this action was not applicable since the device required for the measurement of vibrations has a cost considered high by the maintenance department. This measurement would allow to assess the general condition of the tub in a faster way. Therefore, new actions were defined to verify the normal operation of the equipment by checking the remaining components, making the control of the tank through three new measurements. The first focuses on measuring the wear condition of the inductor, through a monthly preventive maintenance action complemented by a Standard Operating Procedure (SOP) file. The limit value of the resistivity for the inductor has been defined as $2,5 \Omega$, i.e., when lower values are recorded, the component must be replaced. This resistivity value was defined through the supplier's knowledge combined with the experience of the maintenance technicians. The second action aims to control the distance between bars. To this end, a SOP file was created for the replacement of the inductor, where the distance between bars was defined as $0,8 \mathrm{~mm}$, according to the supplier's recommendations. Finally, to control the wear of the tank lining, an easy-to-per- form test was designed. This consists of collecting a cork, placing it at the base of the tub container and measuring the time it takes to travel through the circuit until it reaches the tub outlet. The chosen cork must always have the same treatment and size, so that the measurements are as reliable as possible. At least five measurements must be conducted to obtain the average result that allows to make decisions on the wear and lifespan of the tub. By performing this test in a tub with the coating in good condition, it was found that the ideal time for the cork to travel through the circuit is about 11 seconds, with small oscillations between 10 and 12 seconds ( $11 \pm 1$ second). This verification will be carried out by the equipment operators in a monthly autonomous maintenance action. Additionally, the equipment's potentiometer value was also defined as seven, on a vibration scale from zero to nine, according to the supplier's recommendations.

\subsection{Implementation}

With the analysis carried out for all the different components mentioned above, it was possible to propose twenty improvement actions, of which sixteen were considered for implementation, as shown in Table 5.

\section{Results (Evaluation)}

Regarding the analysis carried out for the set of failures that result in the jamming of the cylinder, it was possible to reduce the impact that they caused on the production time. Therefore, through the progressive introduction of the actions to be implemented, starting in January 2020, it is possible to verify that the situation remained constant until March 2020. 
The average time lost with this malfunction for the period from May 2019 to March 2020 is around 39,14 h. This happens because not all implementations have immediate effects and, also, there is a need for adaptation by operators and maintenance technicians. Thus, in April 2020 it was possible to observe a significant reduction in lost time, going to an average of 25,57 $\mathrm{h}$ in the following two months (April, May and June). This represents a clear decrease of about $34 \%$. The results obtained are summarized in the graph of Figure 10. This information was taken from the production management software MGPRO.

Table 5. Information regarding the implemented actions

\begin{tabular}{|c|c|}
\hline Component & Implementation \\
\hline \multirow{3}{*}{ Gauge hat } & Alerting operators to the importance of complying with the specifications of the hat. \\
\hline & Add the hat height and calibre check to the start of shift checklist. \\
\hline & $\begin{array}{l}\text { Study of a universal adjustable gauge hat with a conical profile to fit all cork calibre } \\
\text { (long term idea). }\end{array}$ \\
\hline \multirow{3}{*}{ Green cords } & Study to measure the theoretical lifetime of the cord (long term idea). \\
\hline & $\begin{array}{l}\text { Preventive maintenance action (with SOP) to check the wear and looseness of the } \\
\text { cord. }\end{array}$ \\
\hline & $\begin{array}{l}\text { Creation of two SOPs to ensure that the cord length and installation (height) are } \\
\text { correct. }\end{array}$ \\
\hline \multirow{3}{*}{ Tub (or vibrating tank) } & $\begin{array}{l}\text { Preventive maintenance action (with SOP) to measure the resistivity of the electric } \\
\text { transformer. }\end{array}$ \\
\hline & $\begin{array}{l}\text { Creation of SOP to replace the electric transformer, ensuring that the distance } \\
\text { between bars is } 0,8 \mathrm{~mm} \text {. }\end{array}$ \\
\hline & Preventive maintenance action (with SOP) to check the wear of the tank lining. \\
\hline \multirow{2}{*}{ Feed cylinder } & Add the pressure gauge check to the start of shift checklist. \\
\hline & Preventive maintenance action (with SOP) to check the component's tightness. \\
\hline \multirow{3}{*}{ Pressure cylinder } & Add the pressure gauge check to the start of shift checklist. \\
\hline & $\begin{array}{l}\text { Preventive maintenance action (with SOP) for the replacement of the bearings when } \\
\text { they reach the theoretical useful life. }\end{array}$ \\
\hline & Add the cylinder height check and adjustment to the start of shift checklist. \\
\hline \multirow{2}{*}{ Knees guides } & Replacement of Teflon knees with reinforced Teflon. \\
\hline & Alerting operators to notify a maintenance technician in case of cork congestion. \\
\hline
\end{tabular}

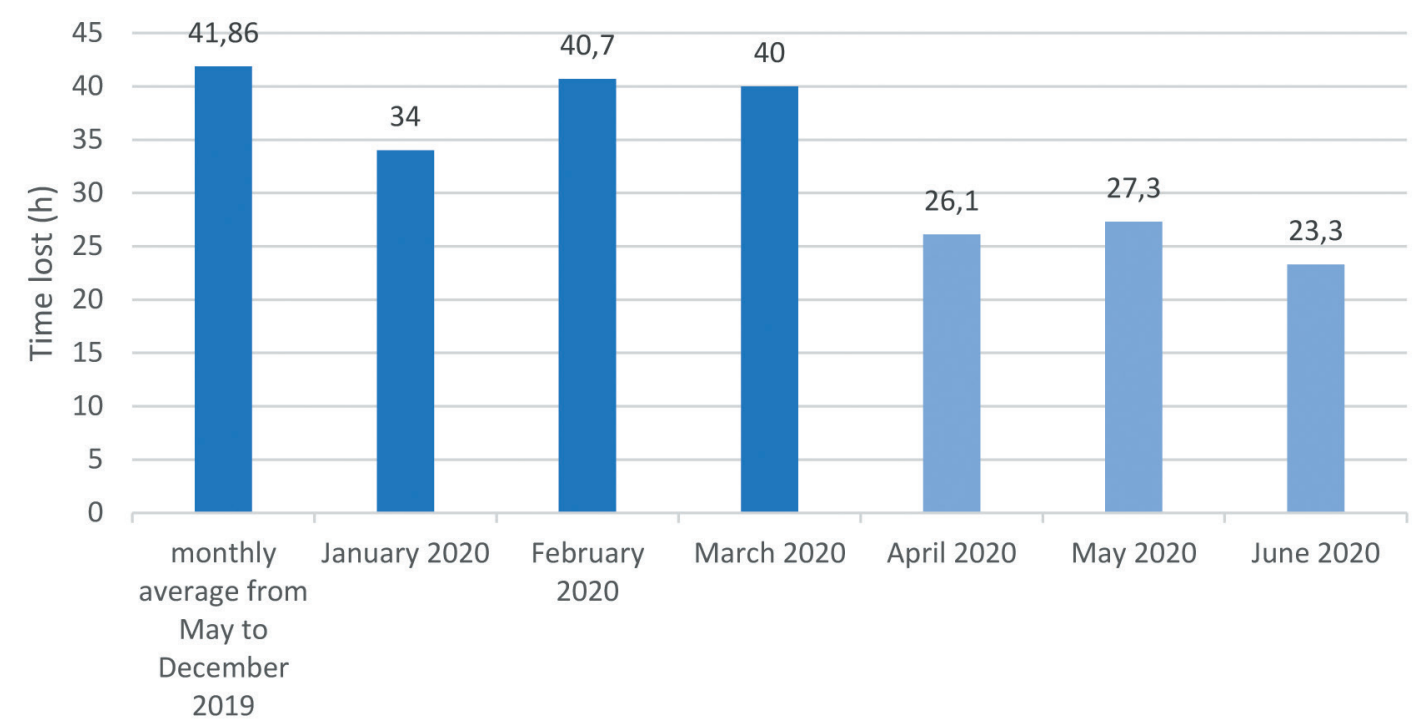

Figure 10. Evolution of time spent on the jamming of the cylinder 
As for the OEE, this intervention in the DSL sector translated into its slight increase. For calculation purposes, this company considers that the quality indicator corresponds to $100 \%$. During the implementation period (from January to June 2020) there was an increase in the OEE indicators, when compared to the period from May to December 2019. For performance, the gain was $1,7 \%$, while for availability, the increase was 3,3\%. Regarding quality, as mentioned above, this indicator did not suffer any improvement since it is considered as being always at the maximum value. This represents an average increase in OEE of $4,6 \%$. This information was taken from the MGPRO production management software.

Table 6 presents the comparison between the world reference values and the current values (between January and June 2020) of the DSL, for the OEE and for its indicators. It is noted that although the performance is already at the required level, there is still a need to positively evolve the availability of this sector to achieve an OEE of world reference.

In Table 6 are presented the machining and setup time of these components for each one of the four groups defined.

\subsection{Monitoring}

The diagram shown in Figure 11 is an important tool for defining the action plan. After choosing the target to intervene, a two-step analysis is carried out. From this analysis, a Pareto's chart emerges, where all possible causes for the different failures are gathered. Depending on the complexity of the problems, the most appropriate tool for critical analysis is chosen, namely Ishikawa or Five Whys. Because the complexity of analysis is relatively low in this case, the Five Whys approach was chosen. Through this analysis, an action plan is defined to counter the causes that contribute to the failures/malfunctions (Key Performance Indicators). The results obtained from the implementation of the action plan, allow a comparison between the results obtained and expected. These results are then monitored with the main objective of understanding whether improvements can be achieved by repeating this procedure for the following malfunctions/workstations/sectors.

This tool can be applied to other studies/industrial sectors, when indicators are assigned to suit the requirements of these new environments, contemplating a way to improve and measure their results. The only difference in the implementation and analysis of the results refers to the Ishikawa or Five Whys analyses, where a more detailed knowledge about the manufacturing processes needs to be used.

\section{Conclusion}

This work aims to show the partial implementation of the TPM, and how acting only in some of its pillars can bring very positive results. However, the challenge of implementing this tool is evident when there is no pre-established basis for TPM implementation or there is no knowledge of the operators about it. Despite the initial lack of knowledge, with increasingly more exciting results, there is a notable increasing involvement of the workers of the intervened department around the TPM methodology, as well as the other departments.

To prove that this tool can be important for the healthy functioning of the company in question, it was decided to point this work to the most problematic sector in terms of breakdowns, the DSL. Of the six workstations considered in this study, the DSL sector accounted for almost $61 \%$ of the total time lost in damage during the period under analysis. With a careful and thorough analysis of the different components of the ES equipment, it was possible to suggest improvement actions to significantly reduce the impact that these breakdowns caused. The various measures implemented in the ES equipment, allowed to obtain a reduction of about $34 \%$ of the time spent on malfunctions, in comparison with the previous period. This is similar to the results obtained by Pinto et al. [3,6], after the application of various improvement activities, which translated into a reduction of equipment downtime by $37.3 \%$, increasing machine availability.

Consequently, this allowed the OEE for the DSL sector to achieve an increase of $4.6 \%$ during the inter-

Table 6. Comparison between the world reference OEE and DSL indicators

\begin{tabular}{lccc}
\hline Indicator & World reference values & DSL values & \\
\hline Availability & $90 \%$ & $87,3 \%$ & $\times$ \\
Performance & $95 \%$ & $95,7 \%$ & $\checkmark$ \\
OEE & $85 \%$ & $83,6 \%$ & $\times$ \\
\hline
\end{tabular}




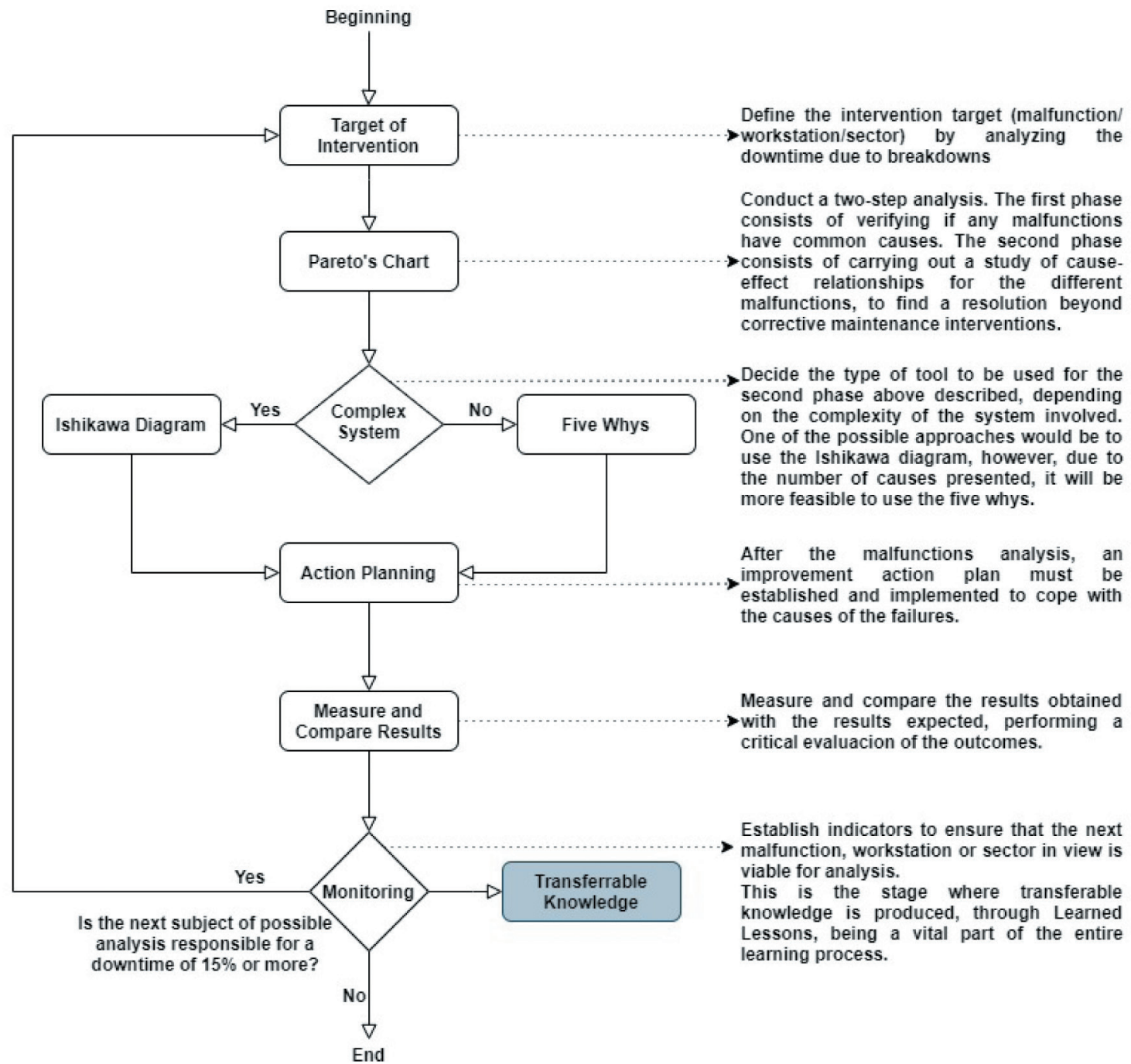

Figure 11. Representation of the used model

vention period, leaving this indicator $(83.7 \%)$ close to the world reference value $(85 \%)$. These results were once again close to those obtained by Pinto et al [3] in the CNC Lathes and CNC Milling Centers, with a gain of $5 \%$ in OEE. Therefore, the results obtained were positive, with room for improvement.

These results allow to state and highlight that the framework established through this work and depicted in Figure 11 is a novel approach to the TPM implementation, which was successfully applied in the cork sector to validate the model, but it can be applied in other sector with similar success, acting as transferrable knowledge extracted from this work.

A crucial aspect for the success of this work (nonmeasurable results), was the availability and willingness of the maintenance technicians to cooperate and support all ideas during all stages of the project. This made it possible to expedite the processes of analysis, discussion and implementation of improvements, being reflected in the results obtained. Therefore, it was clear that the successful implementation of this meth- odology depends on the involvement and motivation of employees during all phases of the project.

Regarding the cork industry, there are few published works in the TPM area. Therefore, it was necessary to resort to other industries to try to establish a term of comparison regarding the results obtained during this study.

In conclusion, the correct implementation of the TPM allows to obtain an improvement of the productive process, through the reduction of malfunctions and breakdowns of the equipment. The involvement of the entire organization in the common objective of constant elimination of losses, provides an environment of continuous improvement and interest of all employees.

Given the successful implementation of the TPM for the DSL sector, it would be very beneficial for the company to involve the entire organization in this philosophy. Since the desire to introduce this methodology must come from the company's management positions, something that does not happen in this case, continuing with this mode of action may 
not provide the best results. As such, for the implementation of the TPM to be effective, it is necessary that all departments are in sync, covering the entire organization. Following the example of what already happens with the $6 \mathrm{~S}$, where each department, with the help of the quality department, is responsible for implementing this tool, it would be beneficial to act in a similar way for the introduction of the TPM. This would provide for the collective involvement of the different sectors so that this methodology can be developed step by step.

Following what was previously suggested, it would be extremely valuable for the company to invest in the training of all employees, instilling them the values of the TPM. This may enable a general change in the company's paradigm, since it is with the operators (who regularly work with the equipment) that the initial understanding of the importance of the TPM philosophy begins.

\section{Funding}

This research did not receive any specific grant from funding agencies in the public, commercial, or not-for-profit sectors.

\section{References}

[1] C. Rosa, F. J. G. Silva, L. P. Ferreira, "Improving the quality and productivity of steel wire-rope assembly lines for the automotive industry," Procedia Manuf., vol. 11, pp. 10351042, 2017.

[2] J. Silva, F. J. G. Silva, R. D. S. G. Campilho, J. C. Sá, L. P. Ferreira, "A model for productivity improvement on machining of components for stamping dies," Int. J. Ind. Eng. Manag., vol. 12, no. 2, pp. 85-101, 2021, doi: 10.24867/IJIEM-2021-2-279

[3] G. Pinto, F. J. G. Silva, N. O. Fernandes, R. Casais, A. Baptista, C. Carvalho, "Implementing a maintenance strategic plan," using TPM methodology," Int. J. Ind. Eng. Manag., vol. 11, no. 3, pp. 192-204, 2020, doi: 10.24867/ IJIEM-2020-3-264

[4] S. Nakajima, Introduction to Total Productive Maintenance (TPM). Portland, OR: Productivity Press, 1988.

[5] K. E. McKone, R. G. Schroeder, K. O. Cua, "Total productive maintenance: a contextual view," J. Oper. Manag., vol. 17, no. 2, pp. 123-144, 1999.

[6] G. F. L. Pinto, F. J. G. Silva, R. D. S. G. Campilho, R. B. Casais, A. J. Fernandes, A. Baptista, "Continuous improvement in maintenance: a case study in the automotive industry involving Lean tools," Procedia Manuf., vol. 39, pp. 1582-1591, 2019.

[7] M. Ben-Daya, S. O. Duffuaa, A. Raouf, J. Knezevic, and D. Ait-Kadi, Handbook of Maintenance Management and Engineering. London, UK: Springer-Verlag, 2009.

[8] I. P. S. Ahuja and J. S. Khamba, "Total productive maintenance:Literature review and directions," International Journal of Quality and Reliability Management, vol. 25, no. 7. pp. 709-756, 2008.
[9] H. Pačaiová and G. Ižaríková, "Base Principles and Practices for Implementation of Total Productive Maintenance in Automotive Industry.," Qual. Innov. Prosper. / Kval. Inovácia Prosper., vol. 23, no. 1, pp. 45-59, 2019.

[10] C. J. Yuik, P. Puvanasvaran, "Development of Lean Manufacturing Implementation Framework in Machinery and Equipment SMEs”, Int. J. Ind. Eng. Manag., Vol. 11, no. 3, pp. 157-169, 2020, doi: 10.24867/ IJIEM-2020-3-261

[11] V. Deac, G. Cârstea, C. Bâgu, and F. Pârvu, "The Modern Approach to Industrial Maintenance Management," Inform. Econ., vol. 14, no. 2, pp. 133-144, 2010.

[12] S. Ferreira, L. Martins, F. J. G. Silva, R. B. Casais, R. D. S. G. Campilho, J. C. Sá, "A novel approach to improve maintenance operations," Procedia Manuf., vol. 51, pp. $1531-1537,2020$.

[13] J. Robertson, "Maintenance of Elevators and Special Lifts," in: Maintenance Engineering Handbook, L. R. Higgins, R. K. Mobley and R. Smith, Eds. New York, NY, USA: McGraw-Hill Companies, Inc., 2002.

[14] J. A. Erkoyuncu, S. Khan, A. L. Eiroa, N. Butler, K. Rushton, and S. Brocklebank, "Perspectives on trading cost and availability for corrective maintenance at the equipment type level,” Reliab. Eng. Syst. Saf., vol. 168, pp. 53-69, 2017.

[15] I. Lopes, M. Figueiredo, V. Sá, "Criticality evaluation to support maintenance management of manufacturing systems," Int. J. Ind. Eng. Manag., vol. 11, no. 1, pp. 3-18, 2020, doi: 10.24867/IJIEM-2020-1-248

[16] C.A. Murad, A.H.A. Melani, M.A.C. Michalski, A.C. Netto, G.F.M. Souza, S.I. Nabet, "OMCTA: A novel knowledge-based technique to evaluate the influence of O\&M actions on maintenance management," Int. J. Ind. Eng. Manag., vol. 11, no. 2, pp. 81-92, 2020, doi: 10.24867/ IJIEM-2020-2-255

[17] C. Jaca, E. Viles, L. Paipa-Galeano, J. Santos, and R. Mateo, "Learning $5 \mathrm{~S}$ principles from Japanese best practitioners: case studies of five manufacturing companies.," Int. J. Prod. Res., vol. 52, no. 15, pp. 4574-4586, 2014.

[18] R. M. Santos, A. C. Sassi, B. M. Sá, S. A. Miguez, and A. A. Pardauil, "Ergonomics Program Management in Tucuruí Hydropower Plant using TPM Methodology," Work, vol. 41, pp. 2822-2830, 2012.

[19] D. D. Shinde and R. Prasad, "Application of AHP for Ranking of Total Productive Maintenance Pillars," Wirel. Pers. Commun., vol. 100, no. 2, pp. 449-462, 2018.

[20] C. Costa, L. Pinto Ferreira, J. C. Sa, and F. J. G. Silva, "Implementation of 5S Methodology in a Metalworking Company,” in DAAAM International, 2018, pp. 001-012.

[21] M. Molenda, "The autonomous maintenance implementation directory as a step toward the intelligent quality management system,” Manag. Syst. Prod. Eng., vol. 24, no. 4, pp. 274-279, 2016.

[22] P. Guariente, I. Antoniolli, L. P. Ferreira, T. Pereira, and F. J. G. Silva, "Implementing autonomous maintenance in an automotive components manufacturer," Procedia Manuf., vol. 13, pp. 1128-1134, 2017.

[23] I. M. Ribeiro, R. Godina, C. Pimentel, F. J. G. Silva, J. C. O. Matias, " Implementing TPM supported by $5 \mathrm{~S}$ to improve the availability of an automotive production line," Procedia Manuf., vol. 38, pp. 1574-1581, 2019.

[24] R. Wudhikarn, "Improving overall equipment cost loss adding cost of quality.," Int. J. Prod. Res., vol. 50, no. 12, pp. 3434-3449, 2012.

[25] V. B. Patel and H. R. Thakkar, "Review Study on Improvement of Overall Equipment Effectiveness through Total Productive Maintenance," J Emerg Technol Innov Res, vol. 1, no. 7, pp. 720-726, 2014. 
[26] A. Moreira, F. J. G. Silva, A. I. Correia, T. Pereira, L. P. Ferreira, F. de Almeida, "Cost reduction and quality improvements in the printing industry," Procedia Manuf., vol. 17, pp. 623-630, 2018.

[27] E. Sousa, F. J. G. Silva, L. P. Ferreira, M. T. Pereira, R. Gouveia, R. P. Silva, "Applying SMED methodology in cork stoppers production," Procedia Manuf., vol. 17, pp. 611-622, 2018.

[28] R. Martins, M. T. Pereira, L. P. Ferreira, J. C. Sá, F. J. G. Silva, "Warehouse operations logistics improvement in a cork stopper factory," Procedia Manuf., vol. 51, pp. 17231729, 2020.

[29] J. Carrasco, D. López, I. Aguilera-Martos, D. García-Gil, I. Markova, M. García-Barzana, M. Arias-Rodil, J. Luengo, F. Herrera, "Anomaly detection in predictive maintenance: A new evaluation framework for temporal unsupervised anomaly detection algorithms," Neurocomputing, vol. 462, pp. 440-452, 2021.

[30] M. D. O. dos Reis, R. Godina, C. Pimentel, F.J. G. Silva,J. C. O. Matias, "TPM strategy implementation in an automotive production line through loss reduction," Procedia Manuf., vol. 38, pp. 908-915, 2019. 